\title{
A nearly fatal primary Epstein-Barr virus infection associated with low NK-cell counts in a patient receiving azathioprine: a case report and review of literature
}

Minna Honkila ${ }^{1,2^{*}}$ (D, Riitta Niinimäki ${ }^{1,2}$, Mervi Taskinen $^{3}$, Outi Kuismin ${ }^{2,4}$, Kaisa Kettunen ${ }^{5}$, Janna Saarela ${ }^{5}$, Sami Turunen ${ }^{1}$, Marjo Renko ${ }^{1,2}$ and Terhi Tapiainen ${ }^{1,2}$

\begin{abstract}
Background: Symptomatic primary Epstein-Barr virus infection is a usually self-limiting illness in adolescents. We present a case of an adolescent who had been receiving azathioprine for inflammatory bowel disease for four years and developed a life-threatening primary Epstein-Barr virus infection successfully treated with rituximab.

Case presentation: An 11-year-old girl presented with chronic, bloody diarrhea. Endoscopic biopsies confirmed a diagnosis of chronic ulcerative colitis with features of Crohn's disease. Azathioprine was initiated after one year due to active colitis. She responded well and remission was achieved. At the age of 16 years she developed a lifethreatening Epstein-Barr virus infection including severe multiple organ failure and was critically ill for 4 weeks in the intensive care unit. Natural killer cells were virtually absent in the lymphocyte subset analysis. Azathioprine was stopped on admission. She was initially treated with corticosteroids, acyclovir and intravenous immunoglobulin. Approximately 30 days after admission, she developed signs of severe hepatitis and pneumonitis and received weekly rituximab infusions for 8 weeks. Primary immunodeficiency was excluded by whole exome sequencing in two independent laboratories. Persistent viremia stopped when the natural killer cell count started to rise, approximately 90 days after the cessation of azathioprine.

Conclusions: We found 17 comparable cases in the literature. None of the previous cases reported in the literature, who had been treated with azathioprine and developed either a severe or a fatal Epstein-Barr virus infection, underwent full genetic and prospective immunological workup to rule out known primary immunodeficiencies. Recently, azathioprine has been shown to cause rather specific immunosuppression, resulting in natural killer cell depletion. Our case demonstrates that slow recovery from azathioprine-induced natural killer cell depletion, 3 months after the stopping of azathioprine, coincided with the clearance of viremia and clinical recovery. Finally, our choice of treating the patient with rituximab, as previously used for patients with a severe immunosuppression and Epstein-Barr virus viremia, appeared to be successful in this case. We suggest testing for Epstein-Barr virus serology before starting azathioprine and measuring natural killer cell counts during the treatment to identify patients at risk of developing an unusually severe primary Epstein-Barr virus infection.
\end{abstract}

Keywords: Epstein-Barr virus infections, Azathioprine, Killer cells, natural, Whole exome sequencing, Rituximab

\footnotetext{
*Correspondence: minna.honkila@oulu.fi

1 Department of Children and Adolescents, Oulu University Hospital, P.O. Box

23, FIN-90029 OYS, Oulu, Finland

${ }^{2}$ PEDEGO Research Unit and Medical Research Center Oulu, University of

Oulu, Oulu, Finland

Full list of author information is available at the end of the article
}

(c) The Author(s). 2019 Open Access This article is distributed under the terms of the Creative Commons Attribution 4.0 International License (http://creativecommons.org/licenses/by/4.0/), which permits unrestricted use, distribution, and reproduction in any medium, provided you give appropriate credit to the original author(s) and the source, provide a link to the Creative Commons license, and indicate if changes were made. The Creative Commons Public Domain Dedication waiver (http://creativecommons.org/publicdomain/zero/1.0/) applies to the data made available in this article, unless otherwise stated. 


\section{Background}

Symptomatic primary Epstein-Barr virus (EBV) infection is a usually self-limiting illness presenting with fever, lymphadenitis, tonsillitis, hepatitis, and splenomegaly in adolescents and young adults. The duration of EBV viremia during primary EBV infection is rather short, while the median half-time for viral elimination is three days [1]. It is well known that after organ or allogenic hematopoietic stem cell transplantation (HSCT), or in patients with primary immunodeficiency, EBV primary infection or reactivation can cause uncontrolled and severe infection and lymphoproliferation. We present a case of an adolescent who had been receiving azathioprine for inflammatory bowel disease for four years who developed a life-threatening EBV infection. In addition, we performed a systematic review of the literature on azathioprine and EBV infection.

\section{Case presentation}

\section{Methods}

We first followed our patient up closely during severe EBV infection using repeated flow cytometry measurements to detect all lymphocyte subpopulations, including natural killer (NK) cell counts. The EBV viral load was measured using a quantitative nucleic acid amplification test (Fig. 1). Immunoglobulin (Ig) $M$ antibodies against viral capsid antigen (VCA) and IgG antibodies to EBV nuclear antigen (EBNA) were measured. Whole exome sequencing (WES) was performed in two independent laboratories, the Institute for Molecular Medicine, Helsinki, Finland, as previously described [2], and Centogene, Germany (www.centogene.com), in order to detect any known primary immunodeficiency. Both the patient and her mother gave their written informed consent to the publication of this case history. We then performed a systematic literature search via PubMed in December 2016 using the terms "Epstein-Barr virus" and "azathioprine". A total 154 possible papers were identified for review, of which 13 were retrieved for detailed examination.

\section{The patient}

An 11-year-old girl presented with chronic, bloody diarrhea. Endoscopic biopsies confirmed a diagnosis of chronic ulcerative colitis with features of Crohn's disease. She was treated first with prednisolone and mesalazine, but azathioprine, $75 \mathrm{mg} /$ day $(2.5 \mathrm{mg} / \mathrm{kg})$, was started after one year on account of continued active colitis. She responded well to this and remission was achieved. At the age of 16 years she was admitted to hospital on account of a high fever and poor general condition. Azathioprine was stopped on account of acute infection, as three-lineage cytopenia was detected on admission: her white blood cell count was $2.5\left(4.5-11 \times 10^{9} / \mathrm{L}\right)$, platelets $38\left(200-450 \times 10^{9} / \mathrm{L}\right)$ and hemoglobin $89 \mathrm{~g} / \mathrm{L}$ (117-155 g/L). Splenomegaly, acute cardiac failure and acute hepatic failure, with

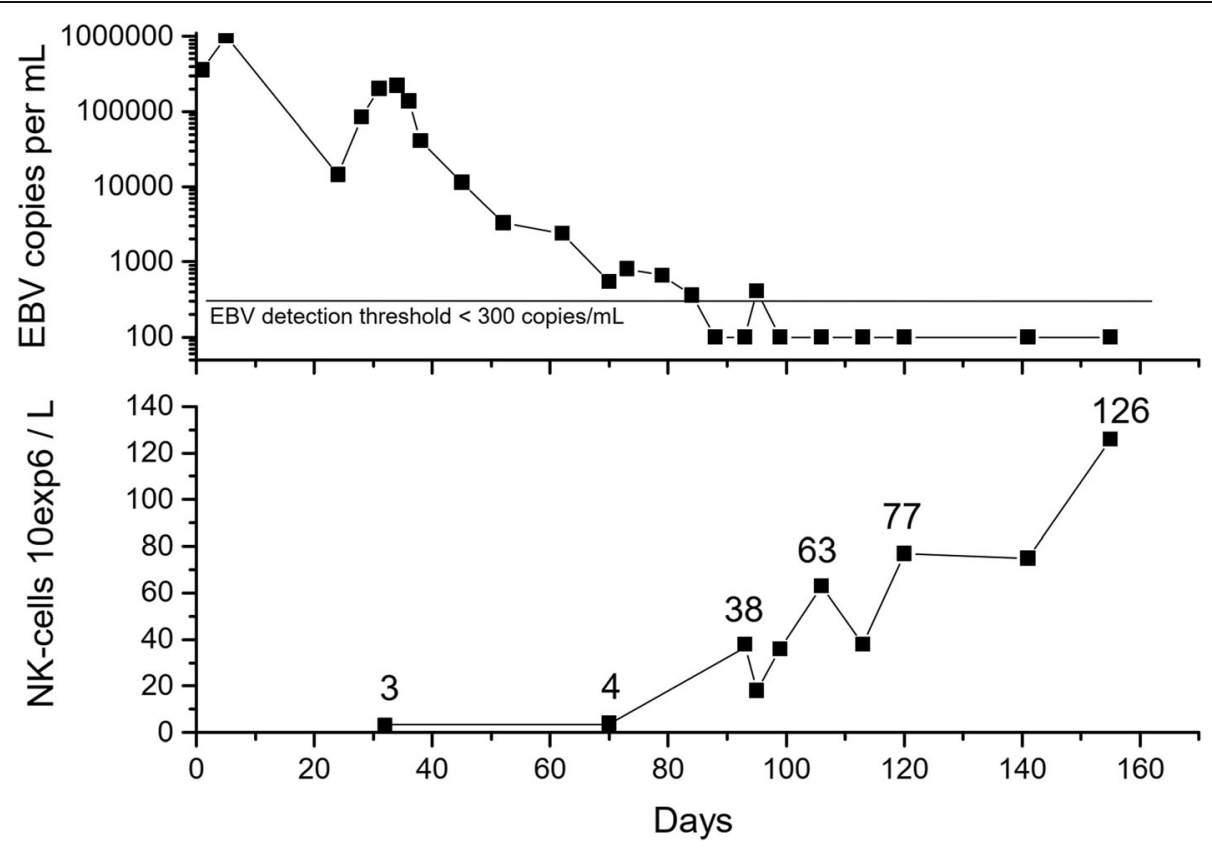

Fig. 1 Epstein-Barr viremia and NK-cell counts after admission in a critically ill adolescent with a primary EBV infection and previously treated with azathioprine for inflammatory bowel disease. Azathioprine was stopped on day 1. NK-cell counts started to rise after 90 days and were normal after 120 days, coinciding with clearance of the viremia. During the course of illness, CD8+ T-cell counts were $1131\left(220-1129 \times 10^{6} / \mathrm{L}\right)$ on day 32 , 2535 on day 70,2487 on day 93 and 2537 on day 106 
$15 \%$ necrosis in a biopsy, were observed in the next few days. Symptoms of encephalitis were present, but a brain MRI was normal. Viral genome examinations by EBV polymerase chain reaction revealed $>350,000$ copies/mL in plasma on admission and $>1$ million copies $/ \mathrm{mL}$ after 4 days of treatment (Fig. 1). A high viral load of $>8$ million copies $/ \mathrm{mL}$ was also detected in the liver biopsy specimen. Tests for IgM antibodies to VCA were positive on admission, whereas IgG antibodies to EBNA were negative, indicating acute EBV infection. She was treated once with rituximab and then with corticosteroids, acyclovir and intravenous immunoglobulin. She developed severe multiple organ failure, including cardiac, hepatic and respiratory failure, and was critically ill for 4 weeks in the intensive care unit. After this treatment in the intensive care unit, approximately 30 days after admission, the viral load started to increase again and she developed signs of severe hepatitis and pneumonitis, so that regular weekly rituximab infusions were given for a total of 8 weeks. Very low NK-cells were noted and the persistent viremia (detection level 300 copies $/ \mathrm{mL}$ ) stopped when the NK-cell count started to rise, approximately 90 days after the cessation of azathioprine (Fig. 1). During the course of illness, CD8+ T-cell counts were $1131\left(220-1129 \times 10^{6} / \mathrm{L}\right)$ on day 32,2535 on day 70, 2487 on day 93 and 2537 on day 106. Due to the prolongation of viremia and hepatitis despite the discontinuation of azathioprine, WES was performed. This did not reveal any known primary immunodeficiency, but the patient was found to be carrying two rare heterozygous variants of the TLR3 and OAS1 genes, in which variants have previously shown to be associated with susceptibility to viral infections. TPMT genotype leading to low enzyme activity was excluded in this case after the patient's recovery. A high total IgG level (>15 g/L) persisted for 6 months after clearance of the viremia, and the low CD19-cell count attributable to the rituximab treatment started to rise 6 months after cessation of the infusions. At the last follow-up visit, she was asymptomatic and healthy and had successfully returned to her studies 6 months after the onset of the EBV infection. She was still in remission with respect to her inflammatory bowel disease without any medication.

\section{Systematic review of the literature}

Examination of the 13 relevant publications yielded a total of 17 corresponding cases, mainly of adolescents or young adults with Crohn's disease or ulcerative colitis who had been treated with azathioprine and developed either severe or fatal EBV infections, or EBV-driven hemophagocytic lymphohistiocytosis or some other lymphoproliferative disorder, excluding lymphomas [315]. Four patients had died [4, 7, 10, 14]. High EBV viremia (>100,000 copies/mL) was documented in five patients [3, 7, 10-12]. NK-cell counts had been made in two out of the 17 patients and either a low count or low NK-cell cytotoxicity had been noted during the acute phase of the illness in both patient cases [3, 13]. CD8+ T-cell counts of the patients were not reported in the literature. Three patients had been successfully treated with repeated rituximab infusions [3, 8, 11]. Most patients had received corticosteroids and also acyclovir or ganciclovir. $\mathrm{X}$-linked lymphoproliferative disease (XLP) was excluded in two male patients by genetic testing $[7,10]$.

\section{Discussion and conclusions}

Azathioprine is widely used for the treatment of Crohn's disease and ulcerative colitis. Our case and systematic literature search confirm that a primary EBV infection can be extremely severe or even fatal for EBV-negative adolescents or young adults receiving azathioprine.

Azathioprine has recently been shown to cause rather specific immunosuppression, resulting in NK-cell $[16,17]$, but not T-cell depletion [17]. Moreover, early-differentiated NK-cells seem to be critical in the immune control of primary EBV infection as this subset of NK-cells expands and restricts lytic EBV infection that is poorly controlled in infectious mononucleosis $[18,19]$. We repeatedly monitored our patient's lymphocyte subpopulation count using flow cytometry and noted an almost total loss of the NK-cell population, whereas the number of CD8+ T-cells were within the normal range. We were thus able to draw a clear time series showing that the clearance of EBV viremia coincided with the normalization of NK-cell counts three to four months after ceasing to administer azathioprine. This supports the idea that azathioprine caused a severe secondary immunodeficiency and a lack of NK-cells, resulting in an uncontrolled EBV infection and hyperinflammation, since NK-cells play a role in down-regulating inflammatory responses [20]. Thus the phenotype observed in our patient mimics the known pathomechanism of congenital hemophagocytic lymphohistiocytosis, which is a hyperinflammatory condition explained by low cytotoxic functioning of the NK-cells or T-cells on account of genetic defects [20]. The risk of hemophagocytic lymphohistiocytosis in children with Crohn's disease, often treated with thiopurines, has been estimated to be 100-fold in a population-based patient series of 5 cases with HLH and inflammatory bowel disease [4]. The risk of lymphoproliferative disorders, including lymphomas, has been reported in a large cohort of inflammatory bowel disease patients to be five-fold in those patients receiving thiopurines [21]. Our findings offer a possible explanation for this observed epidemiological risk. 
Corticosteroids and acyclovir are recommended for the treatment of severe EBV infection. After an organ or HSCT EBV is known to cause a lymphoproliferative disorder which can be treated with rituximab, an anti-CD20 monoclonal antibody, in order to reduce B-cells and stop viremia, since B-cells are the main replication site of Epstein-Barr viruses during infection. In patients with XLP, a primary immunodeficiency leading to uncontrolled EBV infection, severe EBV infection has recently been treated with rituximab before HSCT. We chose to treat our patient with corticosteroids, acyclovir and one dose of rituximab at the onset of the disease. However, as the EBV viral load started to increase again after 1 month despite corticosteroid and acyclovir therapy and she simultaneously developed new signs of severe pneumonitis and hepatitis, we decided to administer rituximab weekly until viremia had been arrested, three months after admission. Donor-derived EBV-specific cytotoxic T-cells are a novel experimental treatment for uncontrolled EBV infections in patients with primary or secondary immunodeficiency [22], and we consequently considered treating our patient with EBV-specific cytotoxic T-cells before she started to respond well to rituximab treatment.

The previous cases reported in the literature had not undergone thorough WES to rule out undiagnosed known primary immunodeficiencies, and even though XLP was not a diagnostic alternative for a female patient, defects in the ITK, STK4, TNFRSF7 and CORO1A genes, for instance, can lead to a life-threatening EBV infection. If a primary immunodeficiency had been diagnosed, the patient could have been considered for treatment with EBV-specific cytotoxic T-cells as a bridge before HSCT. Rapid WES is thus a very useful diagnostic tool in cases of unusually severe EBV infection, in order to exclude primary immunodeficiencies, as these need to be treated with a prompt HSCT.

Our clinical case demonstrates that azathioprine-induced NK-cell depletion could be the reason for a severe, life-threatening primary EBV infection in this context. Achieving immune reconstitution may take several months after the cessation of azathioprine medication. All infectious disease specialists treating adolescents and young adult patients who have been receiving azathioprine should be aware of the risk. Testing for EBV serology before starting azathioprine could help to identify EBV-seronegative adolescents and young adults who might have a high risk of developing an unusually severe primary infection.

\section{Abbreviations}

EBV: Epstein-Barr virus; EBNA: Epstein-Barr virus nuclear antigen; HSCT: Hematopoietic stem cell transplantation; lg: Immunoglobulin; NK: Natural killer; VCA: Viral capsid antigen; WES: Whole exome sequencing

Acknowledgements

Not applicable.
Funding

This case report received no funding.

Availability of data and materials

All data generated or analyzed during this study are included in this article.

\section{Authors' contributions}

$\mathrm{MH}, \mathrm{RN}, \mathrm{ST}, \mathrm{MR}$ and $\mathrm{TT}$ participated in the clinical care of the patient. MT, OK, KK and JS advised and supervised the laboratory testing, interpretation and reporting. $\mathrm{MH}$ and $\mathrm{RN}$ collaborated in the writing of the case report, which was critically reviewed and edited by $\Pi$. All authors approved the final manuscript as submitted.

Ethics approval and consent to participate

Not applicable.

\section{Consent for publication}

Both the patient and her legal guardian gave their written consent to the publication of this case history.

\section{Competing interests}

The authors declare that they have no competing interests.

\section{Publisher's Note}

Springer Nature remains neutral with regard to jurisdictional claims in published maps and institutional affiliations.

\section{Author details}

${ }^{1}$ Department of Children and Adolescents, Oulu University Hospital, P.O. Box 23, FIN-90029 OYS, Oulu, Finland. ${ }^{2}$ PEDEGO Research Unit and Medical Research Center Oulu, University of Oulu, Oulu, Finland. ${ }^{3}$ Division of Pediatric Hematology, Oncology and Stem Cell Transplantation, Helsinki University Hospital, Helsinki, Finland. ${ }^{4}$ Department of Clinical Genetics, Oulu University Hospital, Oulu, Finland. Institute for Molecular Medicine Finland, University of Helsinki, Helsinki, Finland.

Received: 7 February 2019 Accepted: 25 April 2019

Published online: 10 May 2019

\section{References}

1. Balfour HH Jr, Holman CJ, Hokanson KM, et al. A prospective clinical study of Epstein-Barr virus and host interactions during acute infectious mononucleosis. J Infect Dis. 2005;192:1505-12.

2. Sulonen AM, Ellonen P, Almusa $\mathrm{H}$, et al. Comparison of solution-based exome capture methods for next generation sequencing. Genome Biol. 2011;12:R94.

3. Fitzgerald MP, Armstrong L, Hague R, Russell RK. A case of EBV driven haemophagocytic lymphohistiocytosis complicating a teenage Crohn's disease patient on azathioprine, successfully treated with rituximab. J Crohns Colitis. 2013:7:314-7.

4. Biank VF, Sheth MK, Talano J, et al. Association of Crohn's disease, thiopurines, and primary epstein-barr virus infection with hemophagocytic lymphohistiocytosis. J Pediatr. 2011;159:808-12.

5. Gidrewicz D, Lehman D, Rabizadeh S, Majlessipour F, Dubinsky M. Primary EBV infection resulting in lymphoproliferative disease in a teenager with Crohn disease. J Pediatr Gastroenterol Nutr. 2011;52:103-5.

6. Angelucci E, Cesarini M, Caturelli E, Vernia P. EBV hepatitis in a young Crohn's disease patient on prolonged remission with azathioprine. Inflamm Bowel Dis. 2011;17:E1.

7. Ross S, Rajwal SK, Sugarman I, et al. Epstein-Barr virus-associated lymphoproliferative disorder in Crohn disease treated with azathioprine. I Pediatr Gastroenterol Nutr. 2010:51:229-31.

8. Courby S, Fabre B, Salameire D, et al. Multifocal polyclonal Epstein-Barr virus-associated B-cell lymphoproliferative disorder secondary to azathioprine therapy successfully treated with rituximab. Leuk Lymphoma. 2010;51:174-7.

9. Moreira T, Lago P, Salgado M, Pimentel R. Epstein-Barr virus and parvovirus B19 coinfection in a Crohn's disease patient under azathioprine Inflamm Bowel Dis. 2010;16:905-6. 
10. N'guyen $Y$, Andreoletti L, Patey $M$, et al. Fatal Epstein-Barr virus primo infection in a 25-year-old man treated with azathioprine for Crohn's disease. J Clin Microbiol. 2009;47:1252-4.

11. Serrate C, Silva-Moreno M, Dartigues P, et al. Epstein-Barr virus-associated lymphoproliferation awareness in hemophagocytic syndrome complicating thiopurine treatment for Crohn's disease. Inflamm Bowel Dis. 2009;15:1449-51.

12. Hagel S, Bruns T, Kantowski M, Fix P, Seidel T, Stallmach A. Cholestatic hepatitis, acute acalculous cholecystitis, and hemolytic anemia: primary Epstein-Barr virus infection under azathioprine. Inflamm Bowel Dis. 2009;15:1613-6.

13. Francolla KA, Altman A, Sylvester FA. Hemophagocytic syndrome in an adolescent with Crohn disease receiving azathioprine and infliximab. J Pediatr Gastroenterol Nutr. 2008;47:193-5.

14. Posthuma EF, Westendorp RG, Van der Sluys Veer A, Kluin-Nelemans JC, Kluin PM, Lamers CB. Fatal infectious mononucleosis: a severe complication in the treatment of Crohn's disease with azathioprine. Gut. 1995;36:311-3.

15. Larvol L, Soule JC, Le TA. Reversible lymphoma in the setting of azathioprine therapy for Crohn's disease. N Engl J Med. 1994;331:883-4.

16. Bouma $\mathrm{G}$, Baggen JM, van Bodegraven AA, et al. Thiopurine treatment in patients with Crohn's disease leads to a selective reduction of an effector cytotoxic gene expression signature revealed by whole-genome expression profiling. Mol Immunol. 2013;54:472-81.

17. Lord JD, Shows DM. Thiopurine use associated with reduced B and natural killer cells in inflammatory bowel disease. World J Gastroenterol. 2017;23:3240-51.

18. Azzi T, Lünemann A, Murer $A$, et al. Role for early-differentiated natural killer cells in infectious mononucleosis. Blood. 2014;124:2533-43.

19. Chijioke O, Müller A, Feederle R, et al. Human natural killer cells prevent infectious mononucleosis features by targeting lytic Epstein-Barr virus infection. Cell Rep. 2013;5:1489-98.

20. Janka GE, Lehmberg K. Hemophagocytic syndromes--an update. Blood Rev. 2014;28:135-42.

21. Beaugerie L, Brousse N, Bouvier AM, et al. Lymphoproliferative disorders in patients receiving thiopurines for inflammatory bowel disease: a prospective observational cohort study. Lancet. 2009:374:1617-25.

22. Bollard CM, Heslop HE. T cells for viral infections after allogeneic hematopoietic stem cell transplant. Blood. 2016;127:3331-40.

Ready to submit your research? Choose BMC and benefit from:

- fast, convenient online submission

- thorough peer review by experienced researchers in your field

- rapid publication on acceptance

- support for research data, including large and complex data types

- gold Open Access which fosters wider collaboration and increased citations

- maximum visibility for your research: over $100 \mathrm{M}$ website views per year

At BMC, research is always in progress.

Learn more biomedcentral.com/submissions 